\title{
International Journal of Climatology
}

\section{Weekly to multi-month persistence in sets of daily weather patterns over Europe and the North Atlantic Ocean}

\begin{tabular}{|r|l|}
\hline Journal: & International Journal of Climatology \\
\hline Manuscript ID & JOC-18-0526.R2 \\
\hline Wiley - Manuscript type: & Research Article \\
\hline Author: & 08-Nov-2018 \\
\hline & $\begin{array}{r}\text { Komplete List of Authors: } \\
\text { Kilsby, Chris; Newcastle University, School of Engineering } \\
\text { Farder, Hayley; Newcastle University, School of Engineering } \\
\text { Hydraulic and Environmental Systems; Newcastle University, School of } \\
\text { Engineering }\end{array}$ \\
\hline Keywords: & $\begin{array}{l}\text { weather patterns, weather types, circulation types, atmospheric } \\
\text { persistence, meteorological drought, Markov, climatology }\end{array}$ \\
\hline Country Keywords: & United Kingdom Of Great Britain And Northern Ireland \\
\hline &
\end{tabular}


1 Full title: Weekly to multi-month persistence in sets of daily weather patterns over

2 Europe and the North Atlantic Ocean

3 Short title: Weekly to multi-month persistence of European weather patterns

4 Authors: Douglas Richardson ${ }^{a *}$, Christopher G. Kilsby ${ }^{\mathrm{a}}$, Hayley J. Fowler ${ }^{\mathrm{a}}$, András

5 Bárdossy ${ }^{\mathrm{a}, \mathrm{b}}$

6 a School of Engineering, Newcastle University, Newcastle upon Tyne, UK

7 b Institute for Modelling Hydraulic and Environmental Systems, Universität Stuttgart,

$8 \quad$ Stuttgart, Germany

$9{ }^{*}$ Correspondence to: D. Richardson, School of Engineering, Cassie Building, Newcastle

10 University, Newcastle upon Tyne, NE1 7RU, UK. E-mail:

11 d.richardson2@newcastle.ac.uk

12 Keywords: weather patterns; weather types; circulation types; atmospheric persistence;

13 meteorological drought; Markov; climatology; UK 


\section{Abstract}

15 Persistence in time series of daily weather pattern (WP) classifications can provide useful

16 information such as on the memory of broad-scale atmospheric circulation. Despite this,

17 research of WP persistence has lagged behind that exploring their frequencies of occurrence.

18 We develop two methods for identifying persistence in a 167-year time series of WPs defined

19 over the North Atlantic-European domain. The first is an empirical counting technique used to find periods of persistence amongst sets of WPs, with the definition of persistence more

21 relaxed than just consecutive occurrences. We then condition this method on the driest WPs to see if persistence can be used to identify historical drought. The second method uses a

23 Markov model to assess if WP transition probabilities change when conditioned on information up to 20 days prior, without the need for estimating the large number of parameters usually required for high-order Markov chains. Results are compared with a benchmark ensemble of synthetic time series generated using first-order transition probabilities. We show that there were multi-month periods when small sets of WPs dominated, and some of these periods coincided with notable meteorological events, including droughts and storms, such as the mid-1990s drought in northern England and the Burn's Day Storm over southern Scotland in 1990. Some WPs also behave as 'attractors',

31 showing increased probability of reoccurrence despite other WPs occurring in-between.

32 However, we find no link between the persistence statistics of each WP and their flow 33 characteristics, except for those featuring an easterly flow over the UK, which are amongst the most persistent. The benchmark simulation ensemble is unable to reproduce many of the key persistence statistics of the observations, confirming that the persistence is a physical phenomenon. Finally, we discuss the potential processes underpinning WP persistence, such

37 as the effects of large-scale circulation patterns and land-surface feedbacks. 
39 A weather pattern classification comprises a group of weather patterns (WPs; also called weather types, circulation types or circulation patterns), each representing distinct states of atmospheric circulation over a given domain and time-scale (usually daily). They are a useful way of reducing the complexity of the atmosphere and making general predictions of localscale weather variables such as temperature or precipitation. There is a wide range of research using WP classifications, including in historical and future climate change studies (Donat et al., 2010a; Gómez-Gesteira et al., 2011; Lorenzo et al., 2011; Brigode et al.; Fereday et al., 2018), weather prediction (Ferranti et al., 2015; Neal et al., 2016; Vuillaume and Herath, 2017) and in establishing links with a variety of hydro-climatic variables (Trnka et al., 2009; van den Besselaar et al., 2009; Donat et al., 2010b; Giuntoli et al., 2013; Ramos et al., 2013; Wilby and Quinn, 2013; Nied et al., 2014; Prein et al., 2016; Richardson et al., 2018); see Huth et al. (2008) for a full review and for references to literature pre-2008. Uniting the majority of these studies is their focus on WP frequencies of occurrence. By analysing how the frequencies of the WPs change over time or during particular hydrometeorological events, it is possible to identify changes in circulation or those WPs most commonly associated with a type of extreme weather. For example, various authors have studied how WP frequencies change during floods or droughts in the UK (Wilby, 1993; Phillips and McGregor, 1998; Wilby, 1998; Fowler and Kilsby, 2002; Fleig et al., 2011; Burt and Ferranti, 2012; Pattison and Lane, 2012; Wilby and Quinn, 2013; Richardson et al., 2018).

WP persistence has been much less researched and has focussed on changes and trends in mean persistence over time (Stefanicki et al., 1998 ; Werner et al., 2000; Kyselý, 2002;

61 Kyselý and Domonkos, 2006; Kyselý and Huth, 2006; Kyselý, 2007; Blenkinsop et al., 2009;

62 Cahynová and Huth, 2009; Casado et al., 2009; Kučerová et al., 2017). Missing from the

63 literature is analysis of the longest persistent sequences of WPs and the implications for 
atmospheric circulation and hydro-climatic variables. Furthermore, persistence has not to our knowledge been explored in a modelling context except by Fayos and Fayos (2007). Using the objective Lamb Weather Type classification (Lamb, 1972; Jenkinson and Collison, 1977), they developed a neural network forecast model to predict a WP based on the previous five days of WPs. Quantifying persistence in a statistical framework is a useful exercise as it could form the basis of a WP forecast model. Another motivation for this study is to explore a more relaxed definition for persistence. WP persistence has always been defined in previous works as uninterrupted sequences of a single WP (or WP cluster) and as a result these sequences are relatively short, typically with a mean of one week or less (Werner et al., 2000; Kyselý, 2002; Kyselý and Domonkos, 2006; Kyselý and Huth, 2006; Cahynová and Huth, 2009; Casado et al., 2009). An exception found by Kučerová et al. (2017) is for some classifications during the summer over the eastern Mediterranean, which show a mean persistence of up to 52 days, which the authors state reflects the classifications' unrealistic temporal behaviour. We propose a less strict assumption, allowing for limited numbers of different WPs to break up occurrences of the WP(s) under consideration. This means much longer sequences that are broadly characterised, but not exclusively dominated, by one or more WPs could be identified, with little change in local climatic conditions.

We shall explore the persistence of a 167-year daily WP series from a Met Office classification (Neal et al., 2016) using two methods. The first is an empirical counting method used to identify monthly to seasonal persistence in groups of WPs, which will be linked to UK precipitation and notable meteorological events. The second method focuses on shorter-term (up to three weeks) persistence in a novel Markov-model framework used to quantify the likelihood of WPs occurring given their occurrence up to 20 days prior. Results will be compared to a benchmark ensemble of WP time series. Section 2 outlines the WP and 
precipitation data and the two methods for quantifying WP persistence. Section 3 presents the results and discussion points and Section 4 provides conclusions.

\section{Data and methodology}

Data

92

We use a WP classification introduced by Neal et al. (2016) comprising 30 WPs defined objectively using daily mean sea level pressure (MSLP) anomalies over the North Atlantic Ocean and much of Europe. Specifically the domain is $30^{\circ} \mathrm{W}-20^{\circ} \mathrm{E} ; 35^{\circ}-70^{\circ} \mathrm{N}$, with a spatial resolution of $5^{\circ}$. The WP definitions were derived by clustering 154 years (1850 through 2003) of daily MSLP anomaly fields from the European and North Atlantic Daily to multidecadal climate variability (EMULATE) data set (Ansell et al., 2006) into 30 distinct states using simulated annealing. Using these definitions, a time series of WPs was created by assigning daily MSLP anomaly fields from EMULATE to the closest matching WP via the sum-of-squared-differences. The series was extended from 2004 to 2016 using 1200 UTC SLP fields from the European Centre for Medium-Range Weather Forecasts ERA-Interim reanalysis data set (Dee et al., 2011). We use the entire series from 1850 to 2016, referring to the classification as MO-30 and to individual WPs as WP $i$, for $i=1, \ldots 30$. MSLP definitions for the WPs are shown in Figure 1. WPs are ordered according to their historic occurrence between 1850 and 2003: WP1 through WP11 are more common in the summer (April to September) than in the winter (October to March) half-years and vice versa for the remaining WPs (Richardson et al., 2018). MO-30 has previously been used to show the contribution of atmospheric circulation to historical and projected European precipitation variability (Fereday et al., 2018), to predict periods of increased likelihood for UK coastal flooding (Neal et al., 2018) and in analysing aspects of UK precipitation and meteorological drought (Richardson et al., 2018). For precipitation we use the Met Office HadUKP data set from 
1121931 to 2016 (Alexander and Jones, 2000). We standardise the data for the nine regions

113 (Figure 2) by $\boldsymbol{Z}=\boldsymbol{X}-\tilde{x}$, where $\boldsymbol{X}$ is the distribution of daily precipitation for a particular

114 month and region and $\tilde{\boldsymbol{x}}$ is the median of $\boldsymbol{X}$.

115 An empirical counting method for identifying long-term WP persistence

116 The first step in analysing WP persistence is to count on how many consecutive days each

117 WP occurs. Annually, for 24 individual WPs the median persistence is just one day (Figure

118 3). The remaining six WPs have a median persistence of two days. The maximum persistence

119 of any WP over the whole 167 years is 18 days for WP27, followed by 17 days for WP28.

120 These are the only WPs characterised by easterly flow over the UK; this will be discussed in

121 Section 3. Persistence is also linked to seasonality, with out-of-season WPs less likely to

122 persist compared to the annual average (not shown).

123 The length of persistence for individual WPs might be suitable for linking with short-term events such as flooding, but not for events that evolve on longer time-scales, such as drought. To identify longer-term persistence, we therefore develop an empirical counting (EC) method, considering sets of WPs, denoted $S$, that are treated as a single WP. For different sets

127 of $n$ WPs, EC searches the MO-30 time series to find persistent periods of length at least $v$ 128 days containing WPs in the set. We consider that it is likely that long-duration dry and wet events will not be exclusively composed of whichever WPs are in the set under consideration

130 - there will be days on which a different WP occurs that may not be dry or wet (and may

131 indeed be the opposite to the majority of WPs during the event). However, if the number of

132 these days is sufficiently low then the period under consideration may still be dry or wet

133 overall. Therefore, EC permits a certain percentage, $a \%$, of days to be WPs outside the set.

134 Sets of two and three WPs out of the 30 WPs in MO-30 have 435 and 4,060 unique,

135 unordered combinations, respectively. It is feasible to compute persistence periods for each of 
these combinations. For higher-order WP combinations, the task becomes far more expensive in terms of time and computational burden: four- and five-WP sets have 27,405 and 142,506 unique combinations, respectively. Therefore, EC is extended to $n>3$ by introducing a second set of $n_{f}$ fixed WPs, $S_{f}$. For $n<4, S_{f}=\emptyset$, the empty set. We define a persistence period as a time period of at least $v$ days where $(100-a) \%$ of WPs are in $S$ or $S_{f}$. Each WP in $S$ and at least one WP in $S_{f}$ must occur over this period. Using $S_{f} \neq \emptyset$ for $n>3$ WPs then allows identification of much longer periods of persistence, as occurrences of WPs in $S$ broken up by occurrences of WPs in $S_{f}$ will not terminate a persistence period. Moreover, it enables the searching of hypothetically promising sets of more than three WPs while drastically reducing the total number of combinations to process.

1. Define a set of three fixed WPs $S_{f}=\left\{W_{1}=i, W_{2}=j, W_{3}=l\right\}$ and a set of two WPs $S=\left\{W_{4}=m, W_{5}=o\right\}$ for $i, j, l, m, o=1, \ldots, 30$, with $i \neq j \neq l \neq m \neq o$.

2. Set time $t=0$, the length of the moving window in days, $v$, and the percentage of days per moving window allowed to be WPs not in $S$ or $S_{f}$ as $a \%$.

3. Take the $t, \ldots, t+v$ days of the WP time series. If $(100-a) \%$ of WPs in this window are in $S$ or $S_{f}$, each WP in $S$ occurs at least once and at least one WP from $S_{f}$ occurs, then define a new persistence period of length $v$ days and proceed to Step 4 . If not satisfied, set $t=t+1$ and repeat.

4. Set $t=t+1$ and take the $t, \ldots, t+v$ days of the WP time series. If $(100-a) \%$ of WPs in this window are also in $S$ or $S_{f}$, each WP in $S$ occurs at least once and at least one WP from $S_{f}$ occurs, then the length of the persistence period becomes $v^{*}=v+1$ days. Repeat this step until less than $(100-a) \%$ of WPs in $S$ and $S_{f}$ are in the window, at least one WP from $S$ does not occur or no WPs in $S_{f}$ occur. 
5. The persistence period is terminated. Trim the persistence period at either end such that the period must begin and end with a WP in either $S$ or $S_{f}$.

6. Set $t=t+1$ and return to Step 3 until the entire time series has been searched.

7. Choose a new $S^{*} \neq S$ and repeat from Step 3 until every combination of WPs has been processed.

A persistence period of $v^{*}$ days will not necessarily contain at least $v^{*}(100-a) \%$ days featuring the WPs in $S$ or $S_{f}$, but each of the $v$-day windows within the period will have at least $v^{*}(100-a) \%$ days of these WPs. EC effectively treats all WPs in the sets as the same WP, and therefore the identification of multi-WP persistence periods does not necessarily mean that the individual WPs persist within that period. It is possible that a period could consist of many single-day occurrences of WPs in $S$ and/or $S_{f}$.

For each identified persistence period, the observed precipitation anomalies, $Z_{o}$, and expected precipitation anomalies given the WPs, $\boldsymbol{Z}_{e}$, are calculated. The expected precipitation anomalies for each $v$-day persistence period are calculated as follows.

1. Let $\boldsymbol{Y}$ be the time series of precipitation anomalies for a particular region.

2. Set the month, $M$, as that corresponding to the middle day of the persistence period, and let the season, $s$, comprise $M$ and the two months either side.

3. For each day in the persistence period, $T=t, \ldots, t+v$, generate $Q=10,000$ draws with replacement, $\boldsymbol{y}_{T}=\left(y_{1, T}, \ldots, y_{Q, T}\right)$, from the conditional distribution of precipitation anomalies given the WP occurring in $s, \boldsymbol{Y}_{s, W P}$,

4. Over all days, sum the generated samples to obtain a distribution of expected precipitation anomalies, $\boldsymbol{Z}_{\boldsymbol{e}}=\sum_{T=t}^{t+v} \boldsymbol{y}_{\boldsymbol{T}}$. 
182 The observed persistence period precipitation is the sum of the daily anomalies, $Y_{T}$, over the

183 period, given by $Z_{o}=\sum_{T=t}^{t+v} Y_{T}$. While $Z_{e}$ can be estimated for the same period that MO-30 is 184 available for (1850 to 2016), $Z_{o}$ is only available from 1931.

185 We consider two sets of parameters for EC. First, to test for monthly persistence amongst small sets of WPs, we choose $n=3$ WPs, $v=30$ days and $a=10 \%$. As $n<4$ no fixed WPs

187 are required, so we let $S_{f}=\emptyset$. This parameter combination is denoted EC30. These are strict criteria: to be satisfied, three WPs will have to dominate 30-day periods with only three days permitted to be other WPs. The second parameter combination is chosen to seek multi-month persistence. After trying various numbers of WPs in $S$ and $S_{f}$, a suitable compromise between number of WPs and length of persistence is identified as follows. We set $n=3$ WPs, $n_{f}=3$ WPs, $v=60$ days and $a=20 \%$ (the same ratio of $v$ and $a$ as for EC30). We name this parameter combination EC60. Choosing to investigate the link between persistence and drought, we then select the three driest WPs according to UK mean daily precipitation

195 (Richardson et al., 2018) and define $S_{f}=\{$ WP6, WP17, WP25 $\}$. This choice reflects both 196 frequently occurring summer WPs (WP6) and less frequent, wintry WPs (WP17 and WP25).

197 As the three driest WPs, they are unsurprisingly characterised by anticyclonic conditions over 198 the UK (Figure 1).

\section{A Markov model for quantifying persistence}

200 As EC is not a statistical model, it is difficult to use results arising from its application in

201 further applications such as forecasting. Therefore, we take another approach to quantify persistence in MO-30, underpinned more formally by a statistical model. A common way of modelling discrete data is using Markov processes (Norris, 1997) to quantify the probability

204 of state (in this case WP) transitions. As before, we let $W_{t}$ represent a particular WP $i$ on day

$205 t$. Therefore, the first-order Markov assumption is: 


$$
\operatorname{Pr}\left(W_{t} \mid W_{t-1}, W_{t-2}, \ldots, W_{1}\right)=\operatorname{Pr}\left(W_{t} \mid W_{t-1}\right)
$$

207 i.e. the probability of a WP occurring is only dependent on the WP of the previous day. The

208 transition probabilities are given by the transition matrix, $\mathbf{P}$, with each element calculated as

$209 p_{i, j}=\operatorname{Pr}\left(W_{t}=i \mid W_{t-1}=j\right)$, for $i, j=1, \ldots, 30$. The most likely transition for any WP is the

210 same-state transition and the seasonality is also evident, with the lower-numbered, summer

211 WPs more likely to transition between themselves and vice-versa for the winter WPs (Figure

212 4). To increase the number of days influencing each transition, higher-order Markov chains

213 could be considered. However, the number of parameters needed to estimate Markov models

214 increases exponentially with the order, and the sample size of some multi-day transitions

215 could be very small, making their transition probability estimates highly uncertain.

216 Fortunately, for persistence, consideration of all possible transitions to a high order is not

217 necessary; only the return of the WP system to its initial state is of interest. For example, in

218 the second-order case, rather than considering $\operatorname{Pr}\left(W_{t}=i \mid W_{t-1}=j, W_{t-2}=l\right)$

$219, i, j, l=1, \ldots, 30$, it is sufficient to consider $\operatorname{Pr}\left(W_{t}=i \mid W_{t-1}=j, W_{t-2}=i\right)$. Instead of 30

220 permutations given by the values $l$ could take, only one is necessary, that given by $i$.

221 We generalise this idea to higher orders by considering $u \geq 1$ occurrences of $W_{t}=i$ in the $k$ -

222 day period prior to the final transition of $W_{t-1}$ to $W_{t}$. This conditional probability can be

223 expressed as

$$
\operatorname{Pr}\left(W_{t}=i \mid W_{t-1}=j, \quad \sum_{T=t-k-1}^{t-2} \mathrm{I}_{W_{T}}(i) \geq u\right), i, j=1, \ldots, 30
$$

where $\mathrm{I}_{W_{t}}(x)$ is the indicator function defined as

$$
\mathrm{I}_{W_{t}}(x):= \begin{cases}1 & \text { if } x=W_{t} \\ 0 & \text { otherwise }\end{cases}
$$


227 That is, Equation (1) calculates the probability of a WP $i$ occurring given a different WP $j$ on 228 the previous day and $u$ occurrences of WP $i$ in the $k$ days prior to the final transition. For notational simplicity we re-write Equation (1) as

$$
\operatorname{Pr}\left(W_{t}=i \mid W_{t-1}=j, W^{(k, u)}=i\right)
$$

231 The phrase " $k$-day period" will always refer to the time period prior to the final transition,

$232 t-k-1, \ldots, t-2$. Equation (2) reveals whether the occurrence of a particular WP in a given window is likely to be followed by a repeat of this WP, despite other WPs occurring during the $k$-day period and between the $k$-day period and the final $W_{t}$. Furthermore, we can compare these probabilities with the equivalent first-order transition probabilities in $\mathbf{P}$ :

$$
D_{i, j}^{(k, u)}=\operatorname{Pr}\left(W_{t}=i \mid W_{t-1}=j\right)-\operatorname{Pr}\left(W_{t}=i \mid W_{t-1}=j, W^{(k, u)}=i\right) .
$$

Negative $D_{l, j}^{(k, u)}$ occur when $\operatorname{Pr}\left(W_{t}=i \mid W_{t-1}=j, W^{(k, u)}=i\right)>\operatorname{Pr}\left(W_{t}=i \mid W_{t-1}=j\right)$ i.e. when WP $i$ has already occurred at least $u$ times in the $k$-day window, and the resulting probability of $W_{t-1}=j$ transitioning to $W_{t}=i$ is greater than if the sequence was considered independently. These transitions interest us as they indicate persistence. This Markov method will be referred to as MM. The choices of $k$ and $u$ used for MM are shown in Table 1 . We choose higher values of $k$ to investigate whether there is long-range dependence in time, and the range of values chosen for $u$ are to assess the differences between relaxed and strict persistence rules for each $k$.

\section{Comparing with a benchmark ensemble of synthetic WP series}

246 To test whether a time-inhomogeneous first-order Markov model can reproduce observed persistence in the MO-30 data, we conduct a simulation study. Inhomogeneity in time is a necessary imposition, as ignoring the seasonality in MO-30 would result in the underestimation of persistence. For example, as summer is dominated by WP1 through WP11, 
using a non-seasonal transition matrix would result in higher numbers of the other WPs and therefore fewer summer WPs, and hence a decreased likelihood of persistence. We simulate an ensemble of $1000 \mathrm{WP}$ series using the following procedure:

1. Calculate the 12 monthly transition matrices, $\mathbf{P}^{m}, m=1, \ldots, 12$, of MO-30:

$$
p_{i, j}^{m}=\operatorname{Pr}\left(W_{t}=i \mid W_{t-1}=j\right), \text { for } i, j=1, \ldots, 30 \text {. }
$$

2. Generate an initial $W_{1}$ according to its frequency of occurrence and set time $t=1$.

3. Generate a random number $p^{*}$ from the standard uniform distribution $U(0,1)$.

4. Find the index $q$ such that:

$$
\sum_{j=1}^{q-1} p_{i, j}^{m}<p^{*}<\sum_{j=1}^{q} p_{i, j \text { where }}^{m} i=W_{t}
$$

5. Set $W_{t+1}=q$ and $t=t+1$.

6. Repeat steps 3 to 5 until $t=T$, the length of the series to be generated.

261 The benchmark ensemble has reasonable skill at replicating the observed WP frequencies of 262 occurrence (Figure S1). For most WPs and months, the observed frequencies fall within 90\% 263 of the simulated series. There are some significant exceptions. In particular, the simulation methodology underrepresents the occurrences of the two easterly WPs, WP27 and WP28, between January and March. Winter appears to be the least-well simulated season, with WP4, WP8, WP10, WP22, WP23, WP25, WP29 and WP30 all featuring at least one month over- or

267 under-simulated, implying that the first-order transition probabilities are least suited to

268 modelling this season. The simulated series also fail to capture the observed maximum

269 persistence of individual WPs, with $90 \%$ of the ensemble underestimating this statistic for 22 270 WPs (Figure 3).

\section{Results}


273 Despite the transient nature of individual WPs, we can identify multi-month periods where

274 small numbers of WPs dominate. Furthermore, within these periods, the persistence of 275 individual WPs tends be above average. EC30 identifies 67 persistence periods from 54 sets with a median persistence of 31 days (Figure 5a), equivalent to roughly one persistence period every 2.5 years. The longest persistence period was 48 days over winter 1962/63, which was characterised by anticyclonic, often easterly, flow over the UK, as can be seen from the high frequencies of WP25, WP27 and WP28 (Figure 6a). Another example is for 30 days over winter 1990, with WPs in this period suggesting very windy and often stormy conditions, culminating in a 10-day sequence of WP30, which is the longest amount of time this WP has persisted over the whole 167 years (Figure 6b). EC60 identifies 79 persistence periods from 58 sets, with almost half lasting for at least nine weeks (Figure 5b). The two longest examples are almost a full season in length, over summer 1968 and, again, in winter 1962/63 (Figure 6c and d). The former features a near month-long stretch of anticyclonic WPs (WP6, WP9, WP17 and WP25) between $16^{\text {th }}$ July and $10^{\text {th }}$ August. The latter shows how the inclusion of three WPs in $S_{f}$ can extend a persistence period by almost a month (Figures 6a and d). However, the key aspect of this persistence period is the dominance of easterly WPs between $26^{\text {th }}$ December and $9^{\text {th }}$ February, which is completely captured by the shorter persistence period with $S_{f}=\varnothing$ (Figure 6a). All cases in Figure 6 highlight how, within each period, individual WP persistence is greater than average, with many cases of persistence greater than two days (the highest average persistence for any WP). This was particularly stark during the winter of 1995/96 (Figure 6e), with nine-, 11- and 12-day stretches of WP17, WP28 and WP27, respectively. That the behaviour of these daily, typically ephemeral WPs is sometimes reduced down to small sets occurring over such long time-scales is remarkable and suggests that the WPs, and possibly atmospheric circulation in 
general, can be more predictable than usual for months at a time. A dominant easterly flow might be the most likely circumstance under which WP predictability is enhanced, as WP27 and WP28 feature strongly in EC30 and (less so) EC60 persistence periods (Figures 5c and 5d). However, any enhanced predictability during such periods is expected, as there are just two easterly WPs but many more featuring westerly flow (over the UK). Further discussion of the consequences of the small number of easterly WPs is presented later.

EC30 persistence periods are most numerous in winter (December through February; 43 out

304 of 67), while those identified by EC60 are more common in summer (June through August;

30537 out of 79 ), with winter also well-represented ( 25 out of 79$)$; refer to Table 2 . The reason

306 that there are many summer persistence periods of at least 60 days in length, but fewer that

307 are of at least 30 days is due to the percentage of days allowed to be WPs not in $S$ or $S_{f}(10 \%$

308 for EC30 and 20\% for EC60). Although the ratio of this percentage and the minimum

309 persistence period length is the same for both EC30 and EC60, the latter allows for longer

310 sequences of WPs outside $S$ or $S_{f}$ (six consecutive days compared to three days for EC30).

311 Therefore we may conclude that summer persistence periods identified by EC60 have

312 stretches of WPs not in $S$ or $S_{f}$ of length greater than three days, whereas those identified by

313 EC30 do not. The other key feature highlighted by the seasonal distribution of persistence

314 periods is how the number of winter events decreases for EC60 compared to EC30. This is

315 due to the different numbers of WPs associated with each season. In winter, there are more

316 WPs that tend to occur, and so it is less likely there will be persistence of sufficient length to

317 satisfy the conditions of EC60. This is even more the case for the spring and autumn. In these 318 seasons the WP behaviour is transitioning between winter and summer and the frequencies of 319 occurrence are more evenly spread between all 30 WPs.

320 Overall, persistence periods are associated with drier conditions for western and northern 321 regions than for eastern and southern regions. These persistence periods sometimes coincide 
322 with notable meteorological events. Given the WPs that occurred during EC30 persistence 323 periods, the majority of precipitation simulations are below average in NI, NWE, NS and SS 324 and average for the other regions (Figure 7a). This east-west divide is probably due to the 325 predominance of easterly WPs WP27 and WP28 in EC30 periods (Figure 5c), resulting in 326 wetter conditions for eastern UK. Precipitation for individual persistence periods, on the other

327 hand, is likely to be determined largely by the flow direction. Expected and observed anomalies have very similar distributions for both EC30 and EC60, with the main difference being greater $95^{\text {th }}$ percentile anomalies for observed EC30 anomalies (Figure 7). Including 330 the three driest WPs in $S_{f}$ for EC60 does not change the median and lower-tail distribution 331 statistics by very much, with the main effect being a reduction in the upper-tail anomalies, particularly in the observations (Figure 7d). The eastern regions remain wetter than those in the west, again likely due to WP27 and WP28 being amongst the most common WPs in

334 EC60 persistence periods and also to the higher precipitation variability associated with WP25 in eastern regions (Richardson et al., 2018). Examples of easterly-flow persistence are winter 1962/63 (Figures 6a and d) and winter 1995/96 (Figure 6e), with observed and expected precipitation greater for eastern regions. These correspond to notable meteorological events, with the former known to be a particularly cold and dry winter (Prior and Kendon, 2011) and the latter part of the 1995/96 Yorkshire drought (Fowler and Kilsby, 2002). Another example coincident with drought conditions was towards the end of the 2010-

34112 drought (Figure 6f), which was particularly severe for central, southern and eastern

342 England in meteorological, hydrological and agricultural contexts (Kendon et al., 2013). The persistence period occurred over February and March of 2012, with that March being the

344 driest on record since 1953 (Kendon et al., 2013). EC30 also yielded a particularly notable

345 storm: an extremely wet January 1990 (Figure 6b), which culminated in the Burns' Day

346 Storm (McCallum, 1990) over southern Scotland on the $25^{\text {th }}$ and $26^{\text {th }}$ January. However, our 
347 results imply that it is difficult to say anything about precipitation based on WP persistence

348 alone. While there does appear to be a geographical difference (drier conditions in western

349 regions), this may be an artefact caused by the lack of variety of easterly WPs in MO-30; we

350 will discuss this more later.

351

352

353

354

355

356

357

358

359

360

361

362

363

364

365

366

367

368

369

370

371

\section{Markov model results}

For some WPs, their probability of occurrence is increased if they have occurred previously, including situations in which other WPs occur in-between. This holds for different lengths of the $k$-day window for up to almost three weeks. Over all WPs, the more often a WP occurs in this window, the higher probability it has of reoccurring after the final transition. We show results for MM with $k=5$, with stricter persistence rules (i.e. higher $u$ ) yielding more probability in the lower tail of the $D_{i, j}^{(5, u)}$ distributions (Figure $8 \mathrm{a}$ to d). This is also true for other $k$ (not shown). This suggests that when a particular pattern of atmospheric circulation has been dominating over recent days, it is more likely to persist into the future (dependent on the actual synoptic situation represented by the WPs). To identify the WP transitions that are influenced by this type of persistence, we count how often each WP transition is below the $20^{\text {th }}$ percentile of the $D_{l, j}^{(k, u)}$ distributions (for all 23 combinations of $k$ and $u$ ). Persistence of anticyclonic WPs appear to influence each other, for example WP6 shows higher probabilities of reoccurring if the previous WP is WP6, WP17, WP18 or WP25. Similarly, some cyclonic WPs are more likely to persist if the penultimate WP is also cyclonic, such as WP7 preceded by WP7, WP8, WP11, WP22, WP24 or WP28 (Figure 9). We collate these results to identify the most persistent WPs by considering the transitions independent of the penultimate WP, equivalent to summing the counts given by the rows of Figure 9. It appears as though the summer WPs are more persistent than the winter WPs, with WP1 and WP7 the two most persistent (Figure 10a). However, this seasonal divide is also present in the simulated series. When taking the difference between the observed and simulated medians, 
this contrast is less stark (Figure 10b). Accounting for seasonality, the most persistent WPs are WP28, WP16, WP7, WP23, WP18 and WP25. Apart from WP7, these occur more often in winter than summer, although the following three most persistent WPs are all associated with summer (WP2, WP4 and WP6). We do not find a link between WP persistence and the corresponding WP's MSLP definition, with high persistence from WPs that differ by their MSLP anomalies (e.g. cyclonic WP7 and WP28 versus anticyclonic WP18 and WP25) and direction of flow over the UK (e.g. westerly or south-westerly WP7, WP18, WP23; southerly WP16 and south-easterly WP28).

The persistence characteristics outlined previously are not replicated by the first-order transition probabilities. Those WP transitions that are more likely when conditioned on persistence (i.e. when $D_{l, j}^{(k, u)}<0$ ) are more numerous and have higher magnitude transition probabilities for the observations than for the benchmark ensemble. This is shown by the differences between the lower tails of the observed and simulated $D_{i, j}^{(k, u)}$ ECDFs (Figure 8). An exception is how, for higher $k$ and $u$, there is more probability in the lowest part of the distribution for the benchmark, not observed, WP series. This can be likened to 'repelling' behaviour: for longer $k$-day windows with stricter persistence rules, the occurrence of certain WPs in the prior window reduces the chance of these WPs persisting. However, this is likely due to these strict transitions occurring infrequently; we have a much smaller sample size in the observed series than over the 1000 simulated series. Two examples of this behaviour are for $D_{i, j}^{10,6}$ and $D_{i, j}^{15,10}$ (Figures $8 \mathrm{e}$ and f). The simulated ensemble also does not capture the variation in persistence amongst WPs, with the only differences attributable to seasonality: summer WPs are more persistent than winter WPs (boxplots in Figure 10a), whereas the reality is more complex (circles in Figure 10a). For computational reasons we did not run EC for the synthetic series. However, upper-tail statistics of uninterrupted persistence are, for the majority of individual WPs, not reproduced in the ensemble (Figure 3). As discussed earlier, 
397 persistence periods are characterised by above-average persistence of individual WPs and

398 therefore we may infer that the first-order Markov principle is insufficient to replicate

399 persistence periods.

400 WPs with an easterly flow

401 The only two WPs with a distinct easterly flow over the UK, WP27 and WP28, stand out

402 throughout this study for several reasons. They are the WPs with the two longest

403 uninterrupted sequences over the entire record and have the highest or joint-highest mean and

404 median persistence (Figure 3). They are also the most common WPs in EC30 persistence

405 periods (Figure 5c) and are amongst the most common for those identified by EC60 (Figure

406 5d). Furthermore, the first-order Markov assumption is least suited to these two WPs, as they

407 show the greatest difference between observed and simulated maximum persistence (Figure

408 3), and their monthly frequencies are particularly under-simulated in winter (Figure S1). As

409 there are just two easterly WPs, we might expect most daily MSLP fields with an easterly

410 flow to be assigned to them and hence for these WPs to have high within-WP variability. To

411 check this, we calculated the spatial correlation between the WPs and their underlying

412 (concurrent) MSLP fields. These results show that, in fact, WP27 and WP28 have amongst

413 the lowest within-WP variability (Figure S2). As such, the fact that these WPs stand out

414 cannot be attributed to an unsatisfactory assignment process and instead suggests that long

415 periods of atmospheric persistence in the European-North Atlantic domain are characterised

416 by easterly flow patterns closely resembling WP27 and WP28.

\section{4. Conclusions}

418 We have investigated the persistence properties of a time series of $30 \mathrm{WPs}$ defined by MSLP

419 over the North Atlantic Ocean and Europe. By developing an empirical counting method that

420 accounts for more relaxed persistence rules than currently in the literature, we have shown 
421 that there are multi-month periods when normally transient WP behaviour can be reduced down to many occurrences of small sets of WPs. These periods generally result in drier than average conditions for western UK regions and have coincided with notable meteorological events, including droughts. This geographical divide is a result of the predominance of easterly WPs in the identified persistence periods. We also analysed persistence properties using a novel Markov model, which quantified the difference between first-order WP transition probabilities and those conditioned on prior occurrences, without the need for estimating the large numbers of parameters usually required by high-order Markov chains. Some WPs are more likely to reoccur than others, although we could not find a link between their persistence and the MSLP definition.

431 WP frequencies of occurrence are likely modulated by lower-frequency (slowly varying) physical processes, such as large-scale atmospheric teleconnection patterns and landatmosphere interactions. For example, studies have associated variations in the North Atlantic Oscillation (NAO) with changes and trends in the frequencies of WPs from a range of classifications (e.g. Stefanicki et al., 1998; Casado et al., 2009; Kučerová et al., 2017). In particular, during the 1990s the NAO entered a more positive phase (Ostermeier and Wallace, 2003), which means an increased pressure gradient between the teleconnection's high and low pressure centres near the Azores and Iceland, respectively, resulting in a strengthening of 439 the prevailing westerly flow. Coinciding with this, Kučerová et al. (2017) show that WPs 440 featuring zonal (meridional) flow became more (less) frequent over northern and central 441 Europe. Similarly, more frequent northerly WPs over the central and eastern Mediterranean corresponded to an eastward shift of the NAO pressure centres during the same decade (Jung et al., 2003; Beranová and Huth, 2008). To our knowledge, there are no studies formally

444 linking changes in WP persistence to changes in large-scale atmospheric circulation (or other 445 physical mechanisms), offering an opportunity for further research. WP persistence, explored 
446 as both mean persistence over time (see references in Section 1) and longer-term persistence

447 (as analysed in this study) could be linked to variations in atmospheric and oceanic processes

448 thought to influence MSLP in the relevant domains. As highlighted by Kučerová et al.

449 (2017), these kind of climatological studies should be done using multiple, and indeed as

450 many as possible, WP classifications in order to avoid the over-interpretation of results

451 arising from use of a single classification. This merits investigation, as previous research

452 suggest that there are certain conditions that foster atmospheric persistence. The monthly

453 persistence of low-frequency atmospheric circulation patterns, such as the NAO and other

454 teleconnections, is well known (van den Dool and Livezey, 1984; Barnston and Livezey,

455 1987; Perlwitz and Graf, 2001). It is thought that this persistence is partly modulated by

456 stratospheric processes, as anomalies in the stratosphere tend to propagate into the

457 troposphere at lead-times of one to two weeks (Baldwin and Dunkerton, 1998; Thompson et

458 al., 2002). Of particular interest for Europe is how stratospheric anomalies in the northern

459 hemisphere have a similar surface signature to some teleconnection patterns, including the

460 NAO (Baldwin and Dunkerton, 2001).

461 Land-atmosphere feedbacks may also contribute to modifying WP frequencies of occurrence and persistence. For example, the importance of soil moisture in contributing to heatwaves has been well documented, with major European events, such as that over western Russia in

464 2010, being preceded by anomalously dry soils (Fischer et al., 2007; Vautard et al., 2007;

465 García-Herrera et al., 2010; Mueller and Seneviratne, 2012; Quesada et al., 2012; Miralles et al., 2014; Hauser et al., 2016). Relatedly, several studies have linked changes in the mean persistence of WPs from the Grosswetterlagen classification (Hess and Brezowsky, 1952) between 1988 and 1997 to severe central European heatwaves in the 1990s (Kyselý, 2002;

469 Kyselý and Domonkos, 2006; Kyselý, 2007). Interestingly, these studies show that the persistence of all WPs increase during this period, not just those we might typically associate 
471 with heatwaves (i.e. anticyclonic WPs), although as Kyselý and Domonkos (2006) note,

472 persistent atmospheric anomalies can support climate anomalies in both directions. However,

473 Cahynová and Huth (2009) questioned the credibility of changes in WP persistence of this

474 classification in the 1980s, as they were not reflected in analyses of other data sets. This again

475 reinforces the point made by Kučerová et al. (2017) that studies of this nature should utilise

476 multiple classifications.

477 This study may be useful for further research in several ways For example, the methods used

478 to identify and quantify persistence are applicable to any WP classification, making them

479 useful for any region in the world that has such a classification. Furthermore, we have

480 demonstrated the potential to build a statistical forecast model for WP occurrences by

481 showing that their transition probabilities change when conditioned on persistence. While

482 physically-based WP forecast models are in use operationally (Neal et al., 2016), to our

483 knowledge there is no data-driven approach to this problem, except by Fayos and Fayos

484 (2007). Harnessing the persistence shown here may be a viable option for building this

485 model, which may be of value as a way of benchmarking the dynamical systems.

\section{Acknowledgements}

487 We would like to thank two anonymous referees whose comments improved the quality of

488 this article. This work is part of a NERC funded Postgraduate Research Student Studentship

489 NE/L010518/1. Hayley J Fowler is funded by the Wolfson Foundation and the Royal Society

490 as a Royal Society Wolfson Research Merit Award (WM140025) holder. HJF acknowledges

491 support from the INTENSE project supported by the European Research Council (grant ERC-

492 2013-CoG-617329). of Recent Extremes, Atmospheric Science Letters 1(2): 142-150. 
Ansell, T.J., Jones, P.D., Allan, R.J., Lister, D., Parker, D.E., Brunet, M., Moberg, A., Jacobeit, J., Brohan, P., Rayner, N.A., Aguilar, E., Alexandersson, H., Barriendos, M., Brandsma, T., Cox, N.J., Della-Marta, P.M., Drebs, A., Founda, D., Gerstengarbe, F., Hickey, K., Jónsson, T., Luterbacher, J., Ø, N., Oesterle, H., Petrakis, M., Philipp, A., Rodwell, M.J., Saladie, O., Sigro, J., Slonosky, V., Srnec, L., Swail, V., García-Suárez, A.M., Tuomenvirta, H., Wang, X., Wanner, H., Werner, P., Wheeler, D., Xoplaki, E. 2006. Daily Mean Sea Level Pressure Reconstructions for the European-North Atlantic Region for the Period 1850-2003, Journal of Climate 19(12): 2717-2742. 10.1175/jcli3775.1.

Baldwin, M.P., Dunkerton, T.J. 1998. Quasi-biennial modulation of the southern hemisphere stratospheric polar vortex, Geophysical Research Letters 25(17): 3343-3346. doi:10.1029/98GL02445.

508 Baldwin, M.P., Dunkerton, T.J. 2001. Stratospheric Harbingers of Anomalous Weather 509 Regimes, Science 294(5542): 581-584. 10.1126/science.1063315.

510 Barnston, A.G., Livezey, R.E. 1987. Classification, Seasonality and Persistence of Low511 Frequency Atmospheric Circulation Patterns, Monthly Weather Review 115(6): 1083-1126. $512 \quad 10.1175 / 1520-0493(1987) 115<1083$ :csapol $>2.0$. co;2.

513 Beranová, R., Huth, R. 2008. Time variations of the effects of circulation variability modes 514 on European temperature and precipitation in winter, International Journal of Climatology 515 28(2): 139-158. doi:10.1002/joc. 1516.

516 Blenkinsop, S., Jones, P.D., Dorling, S.R., Osborn, T.J. 2009. Observed and modelled 517 influence of atmospheric circulation on central England temperature extremes, International 518 Journal of Climatology 29(11): 1642-1660. doi:10.1002/joc.1807.

519 Brigode, P., Gérardin, M., Bernardara, P., Gailhard, J., Ribstein, P. 2018. Changes in French weather pattern seasonal frequencies projected by a CMIP5 ensemble, International Journal of Climatology. doi:10.1002/joc.5549.

Burt, T.P., Ferranti, E.J.S. 2012. Changing patterns of heavy rainfall in upland areas: a case study from northern England, International Journal of Climatology 32(4): 518-532. 10.1002/joc.2287.

Cahynová, M., Huth, R. 2009. Enhanced lifetime of atmospheric circulation types over Europe: fact or fiction?, Tellus A 61(3): 407-416. doi:10.1111/j.1600-0870.2009.00393.x.

527 Casado, M.J., Pastor, M.A., Doblas-Reyes, F.J. 2009. Euro-Atlantic circulation types and modes of variability in winter, Theoretical and Applied Climatology 96(1): 17-29. 10.1007/s00704-008-0036-2.

530 Dee, D.P., Uppala, S.M., Simmons, A.J., Berrisford, P., Poli, P., Kobayashi, S., Andrae, U., Balmaseda, M.A., Balsamo, G., Bauer, P., Bechtold, P., Beljaars, A.C.M., van de Berg, L., Bidlot, J., Bormann, N., Delsol, C., Dragani, R., Fuentes, M., Geer, A.J., Haimberger, L., Healy, S.B., Hersbach, H., Hólm, E.V., Isaksen, L., Kållberg, P., Köhler, M., Matricardi, M., McNally, A.P., Monge-Sanz, B.M., Morcrette, J.J., Park, B.K., Peubey, C., de Rosnay, P.,

535 Tavolato, C., Thépaut, J.N., Vitart, F. 2011. The ERA-Interim reanalysis: configuration and 536 performance of the data assimilation system, Quarterly Journal of the Royal Meteorological 537 
538 Donat, M.G., Leckebusch, G.C., Pinto, J.G., Ulbrich, U. 2010a. European storminess and 539 associated circulation weather types: future changes deduced from a multi-model ensemble of 540 GCM simulations, Climate Research 42(1): 27-43.

541 Donat, M.G., Leckebusch, G.C., Pinto, J.G., Uwe, U. 2010b. Examination of wind storms 542 over Central Europe with respect to circulation weather types and NAO phases, International 543 Journal of Climatology 30(9): 1289-1300. doi:10.1002/joc.1982.

544 Fayos, J., Fayos, C. 2007. Wind Data Mining by Kohonen Neural Networks, PLOS ONE 545 2(2): e210. 10.1371/journal.pone.0000210.

546 Fereday, D., Chadwick, R., Knight, J., Scaife, A., A. . 2018. Atmospheric Dynamics is the 547 Largest Source of Uncertainty in Future Winter European Rainfall, Journal of Climate 31(3): 548 963-977. 10.1175/jcli-d-17-0048.1.

549 Ferranti, L., Corti, S., Janousek, M. 2015. Flow-dependent verification of the ECMWF 550 ensemble over the Euro-Atlantic sector, Quarterly Journal of the Royal Meteorological 551 Society 141(688): 916-924. 10.1002/qj.2411.

552 Fischer, E.M., Seneviratne, S.I., Lüthi, D., Schär, C. 2007. Contribution of land-atmosphere coupling to recent European summer heat waves, Geophysical Research Letters 34(6): n/an/a. 10.1029/2006GL029068.

558 Fowler, H.J., Kilsby, C.G. 2002. A weather-type approach to analysing water resource

559 drought in the Yorkshire region from 1881 to 1998, Journal of Hydrology 262(1-4): 177-192.

560 http://dx.doi.org/10.1016/S0022-1694(02)00034-3.

561 García-Herrera, R., Díaz, J., Trigo, R.M., Luterbacher, J., Fischer, E.M. 2010. A Review of 562 the European Summer Heat Wave of 2003, Critical Reviews in Environmental Science and 563 Technology 40(4): 267-306. 10.1080/10643380802238137.

564 Giuntoli, I., Renard, B., Vidal, J.P., Bard, A. 2013. Low flows in France and their relationship 565 to large-scale climate indices, Journal of Hydrology 482: 105-118.

566 https://doi.org/10.1016/j.jhydrol.2012.12.038.

567 Gómez-Gesteira, M., Gimeno, L., deCastro, M., Lorenzo, M.N., Alvarez, I., Nieto, R.,

568 Taboada, J.J., Crespo, A.J.C., Ramos, A.M., Iglesias, I., Gómez-Gesteira, J.L., Santo, F.E., 569 Barriopedro, D., Trigo, I.F. 2011. The state of climate in NW Iberia, Climate Research 48(2570 3): 109-144. change for the 2010 heat wave in western Russia, Geophysical Research Letters 43(6): 28192826. doi:10.1002/2016GL068036. 
577 Huth, R., Beck, C., Philipp, A., Demuzere, M., Ustrnul, Z., Cahynová, M., Kyselý, J., Tveito,

578 O.E. 2008. Classifications of Atmospheric Circulation Patterns, Annals of the New York

579 Academy of Sciences 1146(1): 105-152. 10.1196/annals.1446.019.

580 Jenkinson, A.F., Collison, F.P. 1977. An initial climatology of gales over the North Sea,

581 Synoptic climatology branch memorandum 62: 18.

582 Jung, T., Hilmer, M., Ruprecht, E., Kleppek, S., Gulev, S., K., Zolina, O. 2003.

583 Characteristics of the Recent Eastward Shift of Interannual NAO Variability, Journal of

584 Climate 16(20): 3371-3382. 10.1175/1520-0442(2003)016<3371:cotres $>2.0 . c 0 ; 2$.

585 Kendon, M., Marsh, T., Parry, S. 2013. The 2010-2012 drought in England and Wales,

586 Weather 68(4): 88-95. 10.1002/wea.2101.

587 Kučerová, M., Beck, C., Philipp, A., Huth, R. 2017. Trends in frequency and persistence of

588 atmospheric circulation types over Europe derived from a multitude of classifications,

589 International Journal of Climatology 37(5): 2502-2521. doi:10.1002/joc.4861.

590 Kyselý, J. 2002. Temporal fluctuations in heat waves at Prague-Klementinum, the Czech

591 Republic, from 1901-97, and their relationships to atmospheric circulation, International

592 Journal of Climatology 22(1): 33-50. doi:10.1002/joc.720.

593 Kyselý, J. 2007. Implications of enhanced persistence of atmospheric circulation for the

594 occurrence and severity of temperature extremes, International Journal of Climatology 27(5):

595 689-695. doi:10.1002/joc.1478.

596 Kyselý, J., Domonkos, P. 2006. Recent increase in persistence of atmospheric circulation 597 over Europe: comparison with long-term variations since 1881, International Journal of 598 Climatology 26(4): 461-483. doi:10.1002/joc.1265.

599 Kyselý, J., Huth, R. 2006. Changes in atmospheric circulation over Europe detected by 600 objective and subjective methods, Theoretical and Applied Climatology 85(1): 19-36. 601 10.1007/s00704-005-0164-X.

602 Lamb, H. 1972. British Isles weather types and a register of the daily sequence of circulation 603 patterns 1861-1971, Geophysical Memoirs 116: 85.

604 Lorenzo, M.N., Ramos, A.M., Taboada, J.J., Gimeno, L. 2011. Changes in Present and Future 605 Circulation Types Frequency in Northwest Iberian Peninsula, PLOS ONE 6(1): e16201. 606 10.1371/journal.pone.0016201.

607 McCallum, E. 1990. The Burns' Day Storm, 25 January 1990, Weather 45(5): 166-173. 608 10.1002/j.1477-8696.1990.tb05607.x.

609 Miralles, D.G., Teuling, A.J., van Heerwaarden, C.C., Vilà-Guerau de Arellano, J. 2014.

610 Mega-heatwave temperatures due to combined soil desiccation and atmospheric heat

611 accumulation, Nature Geoscience 7: 345. 10.1038/ngeo2141.

612 Mueller, B., Seneviratne, S.I. 2012. Hot days induced by precipitation deficits at the global

613 scale, Proceedings of the National Academy of Sciences 109(31): 12398-12403.

614 10.1073/pnas.1204330109. 
615 Neal, R., Dankers, R., Saulter, A., Lane, A., Millard, J., Robbins, G., Price, D. 2018. Use of 616 probabilistic medium- to long-range weather-pattern forecasts for identifying periods with an 617 increased likelihood of coastal flooding around the UK, Meteorological Applications. 618 doi:10.1002/met.1719.

619 Neal, R., Fereday, D., Crocker, R., Comer, R.E. 2016. A flexible approach to defining 620 weather patterns and their application in weather forecasting over Europe, Meteorological 621 Applications 23(3): 389-400. 10.1002/met.1563.

622 Nied, M., Pardowitz, T., Nissen, K., Ulbrich, U., Hundecha, Y., Merz, B. 2014. On the relationship between hydro-meteorological patterns and flood types, Journal of Hydrology 519: 3249-3262. https://doi.org/10.1016/j.jhydrol.2014.09.089.

Norris, J.R. (1997) Markov Chains. Cambridge: Cambridge University Press.

Ostermeier, G.M., Wallace, J.M. 2003. Trends in the North Atlantic Oscillation-Northern Hemisphere Annular Mode during the Twentieth Century, Journal of Climate 16(2): 336341. 10.1175/1520-0442(2003)016<0336:titnao >2.0.co;2.

Pattison, I., Lane, S.N. 2012. The relationship between Lamb weather types and long-term changes in flood frequency, River Eden, UK, International Journal of Climatology 32(13): 1971-1989. 10.1002/joc.2415.

Perlwitz, J., Graf, H.F. 2001. The variability of the horizontal circulation in the troposphere and stratosphere - a comparison, Theoretical and Applied Climatology 69(3): 149-161. $10.1007 / \mathrm{s} 007040170021$.

Phillips, I.D., McGregor, G.R. 1998. The utility of a drought index for assessing the drought

636 hazard in Devon and Cornwall, South West England, Meteorological Applications 5(4): 359637 372. 10.1017/S1350482798000899.

638 Prein, A.F., Holland, G.J., Rasmussen, R.M., Clark, M.P., Tye, M.R. 2016. Running dry: The 639 U.S. Southwest's drift into a drier climate state, Geophysical Research Letters 43(3): 1272640 1279. 10.1002/2015GL066727.

641 Prior, J., Kendon, M. 2011. The UK winter of 2009/2010 compared with severe winters of 642 the last 100 years, Weather 66(1): 4-10. 10.1002/wea.735.

643 Quesada, B., Vautard, R., Yiou, P., Hirschi, M., Seneviratne, S.I. 2012. Asymmetric

644 European summer heat predictability from wet and dry southern winters and springs, Nature

645 Climate Change 2: 736. 10.1038/nclimate1536

646 https://www.nature.com/articles/nclimate1536\#supplementary-information.

647 Ramos, A.M., Pires, A.C., Sousa, P.M., Trigo, R.M. 2013. The use of circulation weather 648 types to predict upwelling activity along the western Iberian Peninsula coast, Continental 649 Shelf Research 69: 38-51. https://doi.org/10.1016/j.csr.2013.08.019.

650 Richardson, D., Fowler, H.J., Kilsby, C.G., Neal, R. 2018. A new precipitation and drought 651 climatology based on weather patterns, International Journal of Climatology 38(2): 630-648. $65210.1002 /$ joc.5199. 
653

654

655

656

657

658

659

660

661

662

663

664

665

666

667

668

669

670

671

672

673

674

675

676

677

678

679

680

681

682

683

684

685

686

687

688

689

690

691
Seneviratne, S.I., Corti, T., Davin, E.L., Hirschi, M., Jaeger, E.B., Lehner, I., Orlowsky, B., Teuling, A.J. 2010. Investigating soil moisture-climate interactions in a changing climate: A review, Earth-Science Reviews 99(3): 125-161.

https://doi.org/10.1016/j.earscirev.2010.02.004.

Stefanicki, G., Talkner, P., Weber, R.O. 1998. Frequency Changes of Weather Types in the Alpine Region since 1945, Theoretical and Applied Climatology 60(1): 47-61. $10.1007 / \mathrm{s} 007040050033$.

Thompson, D.W.J., Baldwin, M.P., Wallace, J.M. 2002. Stratospheric Connection to Northern Hemisphere Wintertime Weather: Implications for Prediction, Journal of Climate 15(12): 1421-1428. 10.1175/1520-0442(2002)015<1421:sctnhw $>2.0$.co;2.

Trnka, M., Kyselý, J., Možný, M., Dubrovský, M. 2009. Changes in Central-European soil-moisture availability and circulation patterns in 1881-2005, International Journal of Climatology 29(5): 655-672. doi:10.1002/joc.1703.

van den Besselaar, E.J.M., Klein Tank, A.M.G., van der Schrier, G. 2009. Influence of circulation types on temperature extremes in Europe, Theoretical and Applied Climatology 99(3): 431. 10.1007/s00704-009-0153-6.

van den Dool, H.M., Livezey, R.E. 1984. Geographical Distribution and Seasonality of Month-to-Month Correlation of Monthly Mean $700 \mathrm{mb}$ Heights, Monthly Weather Review 112(3): 610-615. 10.1175/1520-0493(1984)112<0610:gdasom>2.0.co;2.

Vautard, R., Yiou, P., D'Andrea, F., de Noblet, N., Viovy, N., Cassou, C., Polcher, J., Ciais, P., Kageyama, M., Fan, Y. 2007. Summertime European heat and drought waves induced by wintertime Mediterranean rainfall deficit, Geophysical Research Letters 34(7): n/a-n/a. 10.1029/2006GL028001.

Vuillaume, J.-F., Herath, S. 2017. Improving global rainfall forecasting with a weather type approach in Japan, Hydrological Sciences Journal 62(2): 167-181. 10.1080/02626667.2016.1183165.

Werner, P.C., Gerstengarbe, F.W., Fraedrich, K., Oesterle, H. 2000. Recent climate change in the North Atlantic/European sector, International Journal of Climatology 20(5): 463-471. doi:10.1002/(SICI)1097-0088(200004)20:5<463::AID-JOC483>3.0.CO;2-T.

Wilby, R.L. 1993. The influence of variable weather patterns on river water quantity and quality regimes, International Journal of Climatology 13(4): 447-459. 10.1002/joc.3370130408.

Wilby, R.L. 1998. Modelling low-frequency rainfall events using airflow indices, weather patterns and frontal frequencies, Journal of Hydrology 212-213: 380-392. http://dx.doi.org/10.1016/S0022-1694(98)00218-2.

Wilby, R.L., Quinn, N.W. 2013. Reconstructing multi-decadal variations in fluvial flood risk using atmospheric circulation patterns, Journal of Hydrology 487: 109-121. http://dx.doi.org/10.1016/j.jhydrol.2013.02.038. 


\section{$692 \quad$ Figure captions}

693 Figure 1: Weather patterns in MO-30. Shading indicates mean sea level pressure (MSLP)

694 anomalies. The black contours are isobars showing the absolute MSLP values associated with 695 each weather pattern, with the centres of high and low pressure also indicated.

696 Figure 2: HadUKP daily precipitation regions.

697 Figure 3: Box plots show the distribution of consecutive occurrences of each WP. Black

698 circles represent the $90^{\text {th }}$ percentile of the distribution of maximum consecutive occurrences

699 from the 1000 simulated series. A simulated value less than the observed maximum indicates

700 that $90 \%$ of the simulated series fail to capture the persistence of the observed series.

701 Figure 4: First-order transition probabilities for MO-30 WPs.

702 Figure 5: a) and b) show box plots and the underlying data for the number of days in each

703 persistence period for EC30 and EC60. Whiskers are 1.5 times the interquartile range beyond 704 the $25^{\text {th }}$ and $75^{\text {th }}$ percentiles. c) and d) are counts of how often each WP appears in the 705 persistence period sets.

706 Figure 6: WP time series (top), with expected precipitation anomalies derived from WPs and 707 observed precipitation anomalies (bottom). Plotted for two EC30 persistence periods during 708 a) winter 1962/63 and b) winter 1990 and four EC60 persistence periods during c) summer 709 1968, d) winter 1962/63, e) winter 1995/96 and f) winter/early spring 2012.

710 Figure 7: Boxplots of a) and b) expected, and c) and d) observed precipitation anomalies

711 during persistence periods for a) and c) EC30, and b) and d) EC60. Expected anomalies are

712 sampled from the distributions of precipitation anomalies for WPs occurring in each

713 persistence period. Whiskers represent the $5^{\text {th }}$ and $95^{\text {th }}$ percentiles. 
714 Figure 8: ECDFs for $D_{i, j}^{5, u}$ with a) $u=1$, b) $u=2$, c) $u=3$, d) $u=4$, and for e) $D_{i, j}^{(10,6)}$ and f)

$715 D_{i, j}^{(15,10)}$ for observed (solid line) and simulated (dashed line) series.

716 Figure 9: Counts of how often each individual value (i.e. WP transition) in the $D_{i, j}^{(k, u)}$

717 distribution is below the $20^{\text {th }}$ percentile, over all $k$ and $u$.

718 Figure 10: a) Independent of the penultimate WP $j$, how often each value (i.e. WP transition)

719 in the $D_{l, j}^{(k, u)}$ distribution is below the $20^{\text {th }}$ percentile, over all $k$ and $u$. Observed series

720 represented by the black circles and 1000 simulated series by the boxplots. Whiskers are the

$7215^{\text {th }}$ and $95^{\text {th }}$ percentiles. b) Observed counts minus median of the simulated counts.

722 Table 1: Choices of window length, $k$, and strictness of persistence, $u$, for MM.

723 Table 2: Number of persistence periods beginning in each month.

724 Supporting Information

725 Figure S1: Frequencies of MO-30 WPs by month for the observed series (grey circles) and

7261000 simulated series (boxplots). Whiskers are the $5^{\text {th }}$ and $95^{\text {th }}$ percentiles.

727 Figure S2: Boxplots showing correlation between each WP and the concurrent underlying 728 SLP anomaly fields $1850-2016$. Whiskers are the $5^{\text {th }}$ and $95^{\text {th }}$ percentiles. 


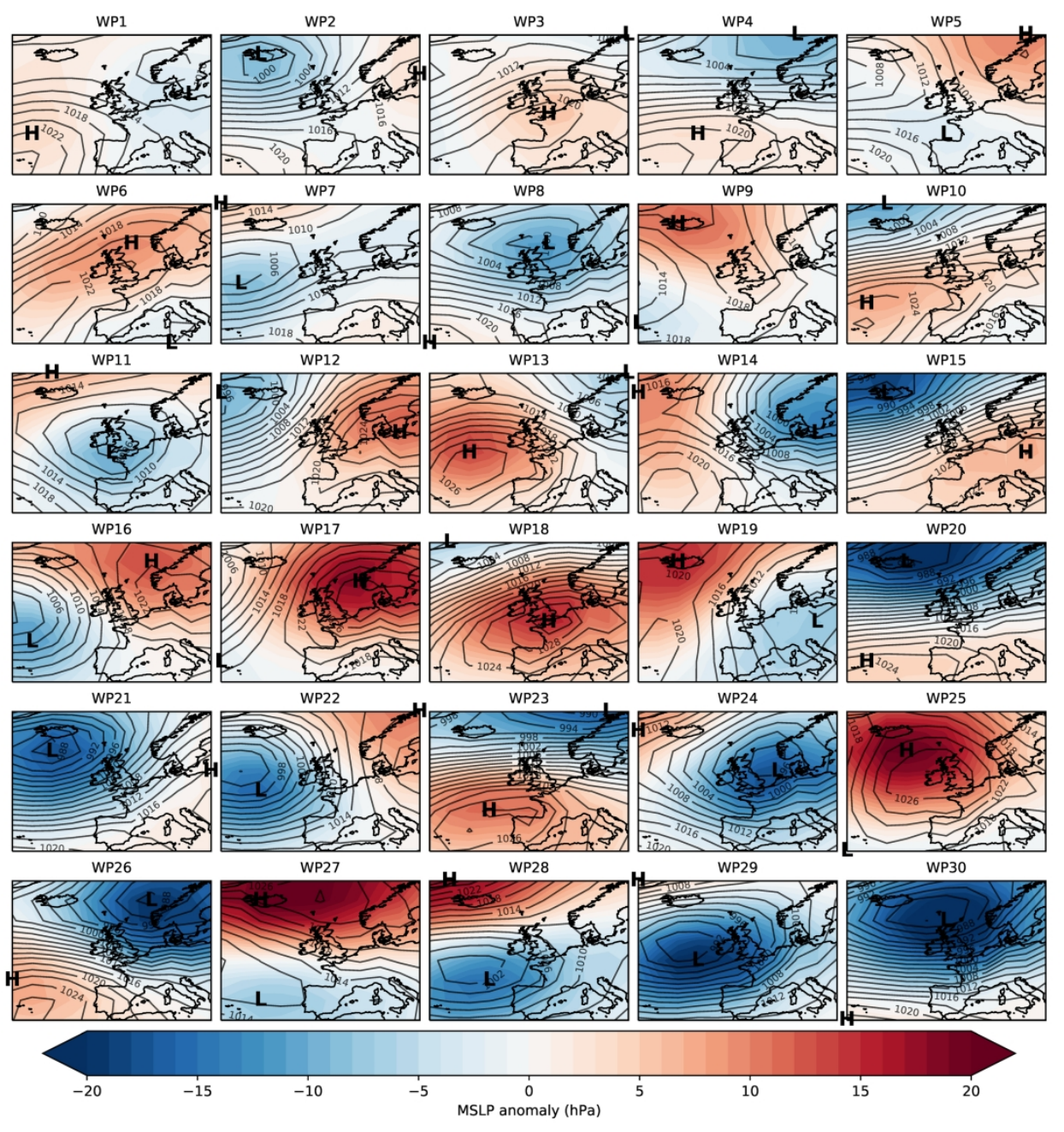

Figure 1

$258 \times 282 \mathrm{~mm}(300 \times 300 \mathrm{DPI})$ 


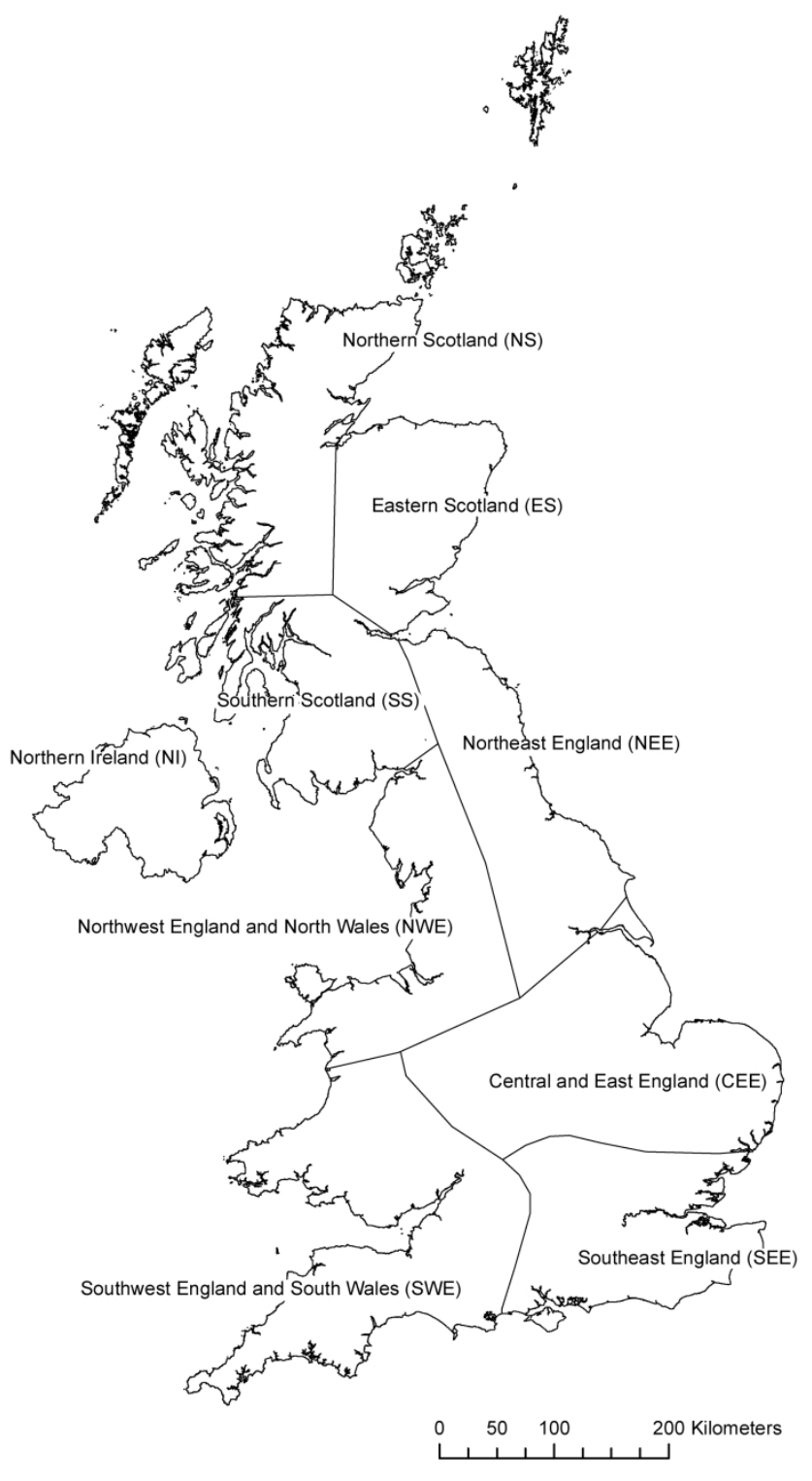

Figure 2

$275 \times 383 \mathrm{~mm}(300 \times 300 \mathrm{DPI})$ 


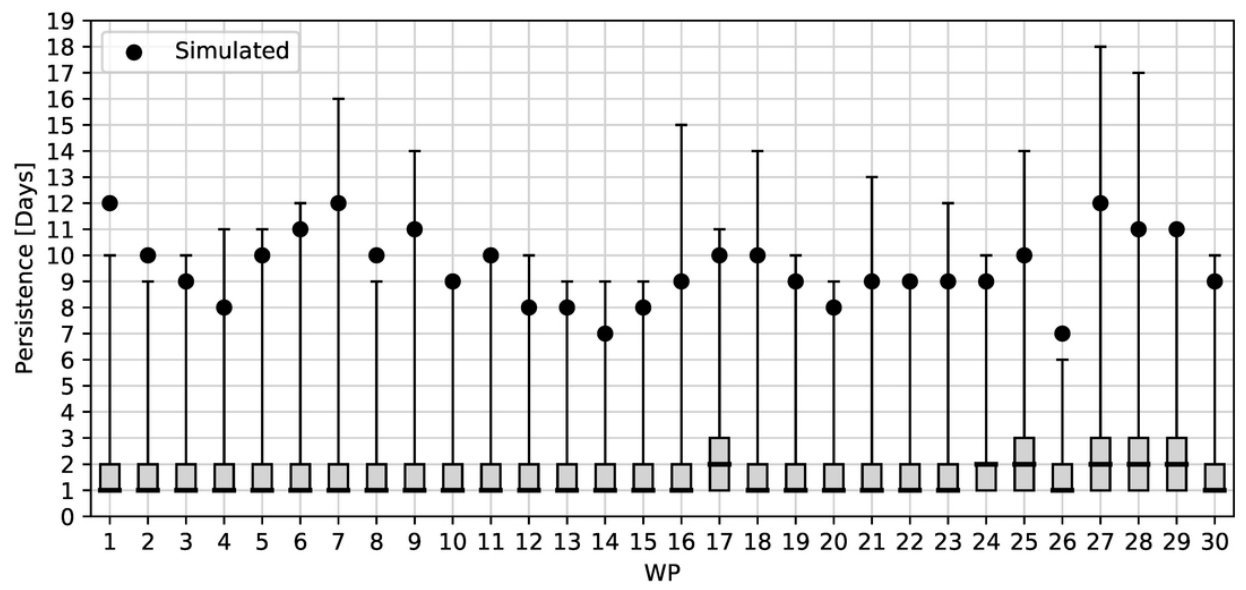

Figure 3

$97 \times 46 \mathrm{~mm}(300 \times 300 \mathrm{DPI})$ 


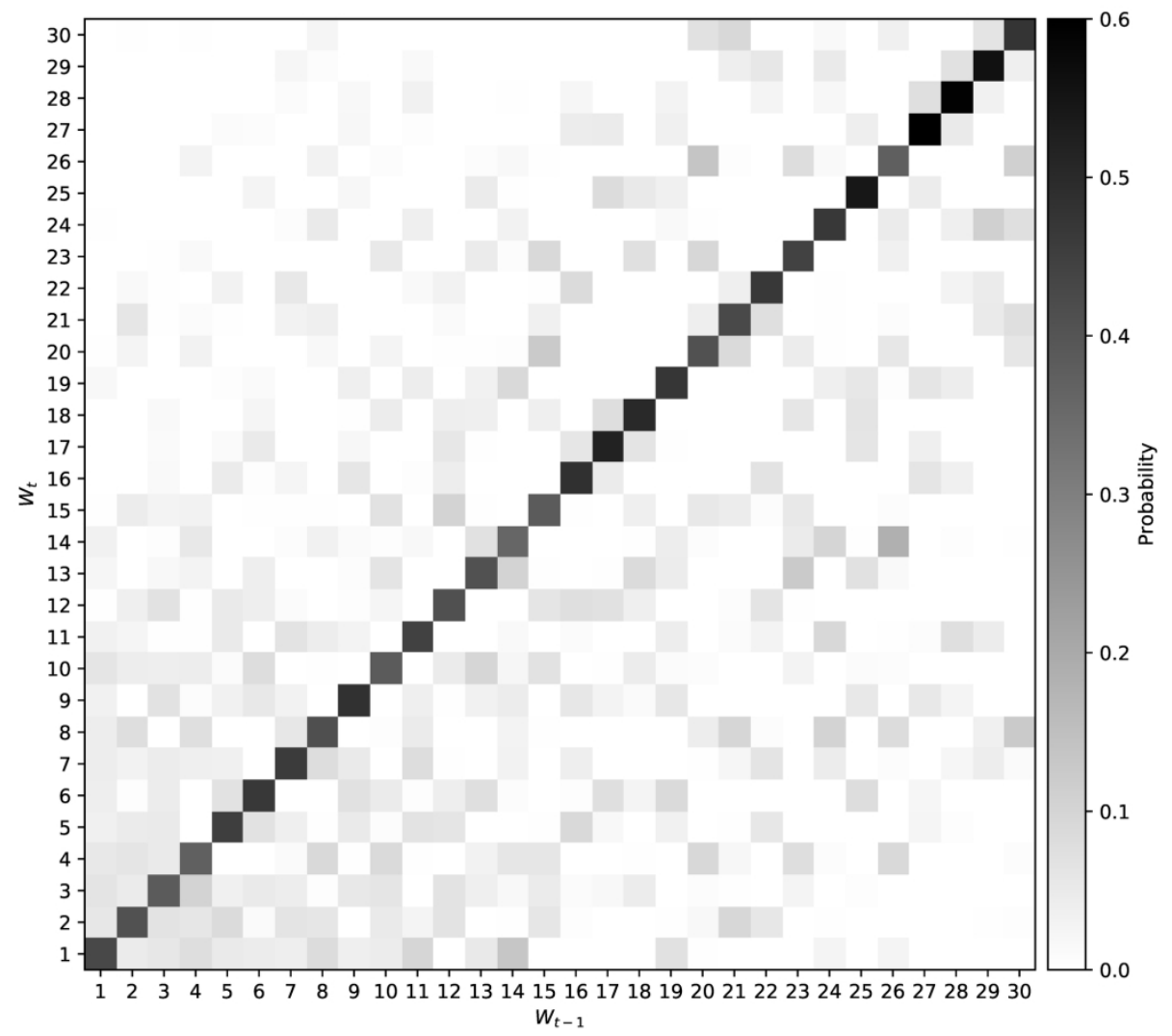

Figure 4

$195 \times 167 \mathrm{~mm}(300 \times 300 \mathrm{DPI})$ 

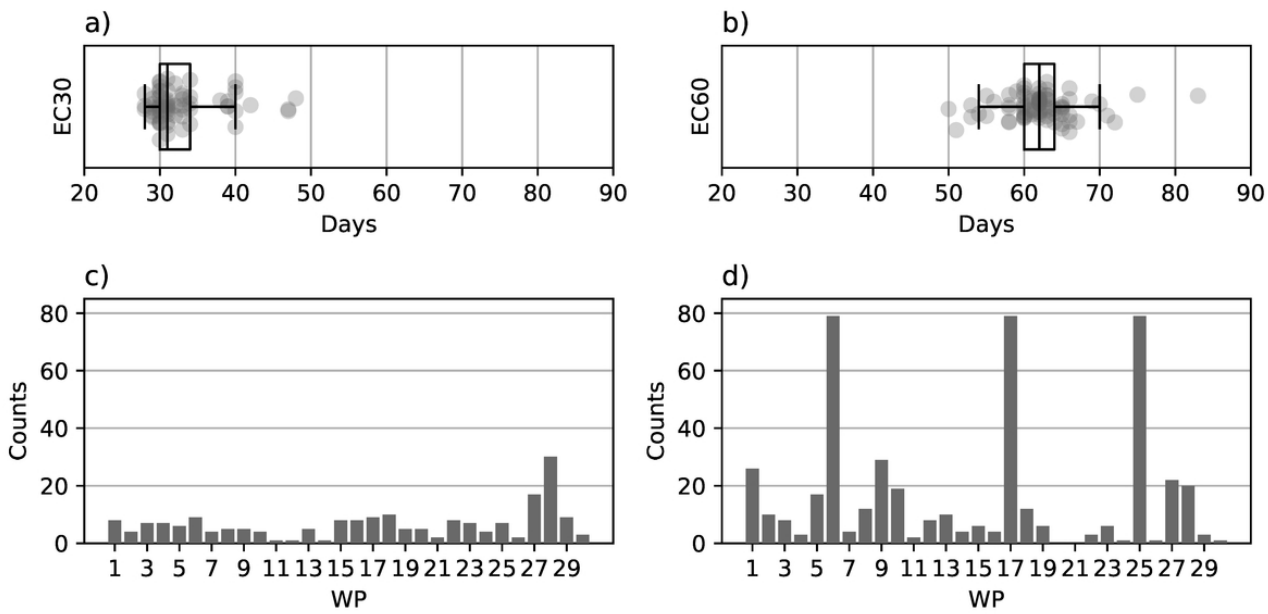

Figure 5

$101 \times 50 \mathrm{~mm}(300 \times 300 \mathrm{DPI})$ 

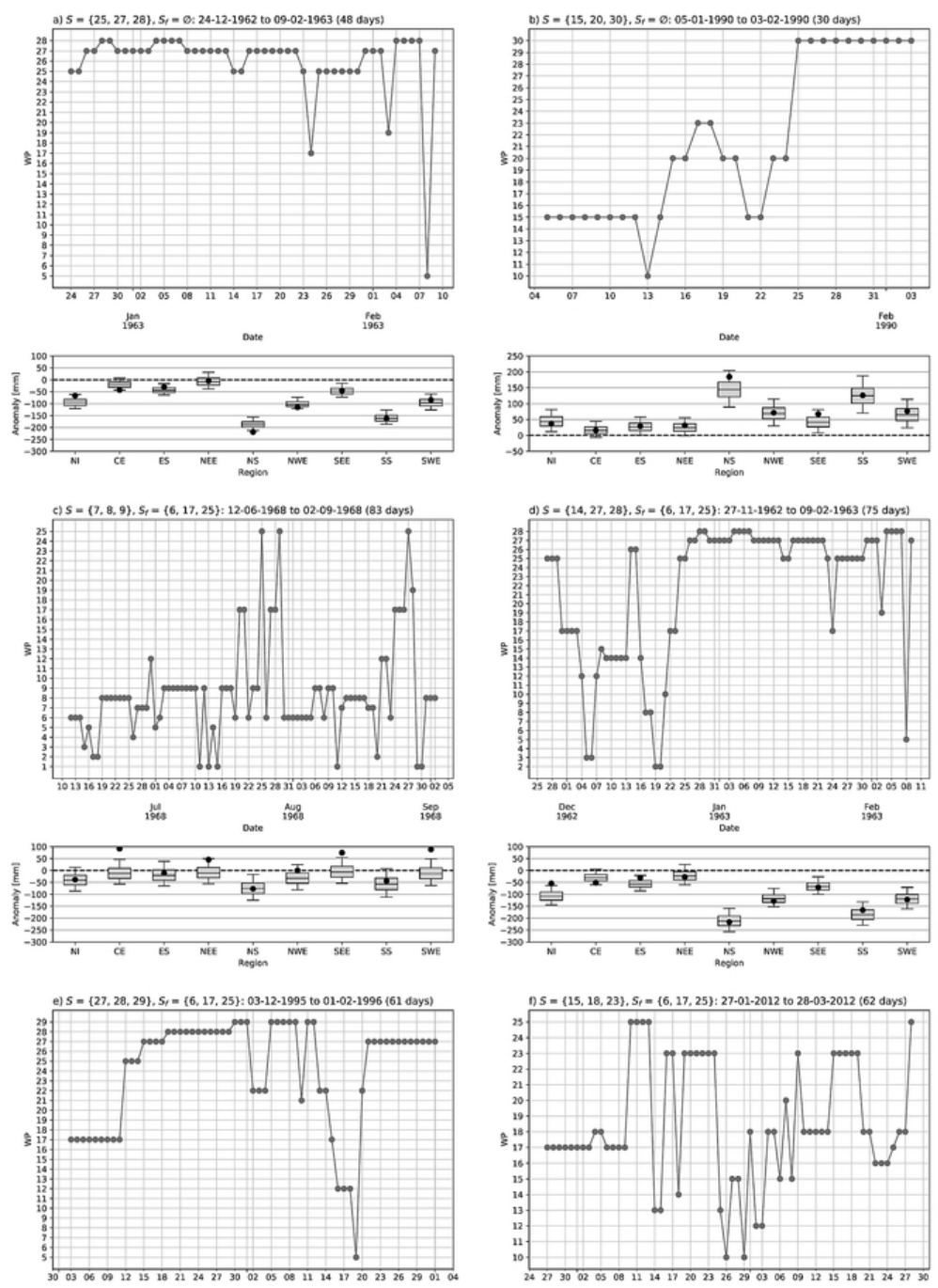

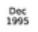

$190 \%$
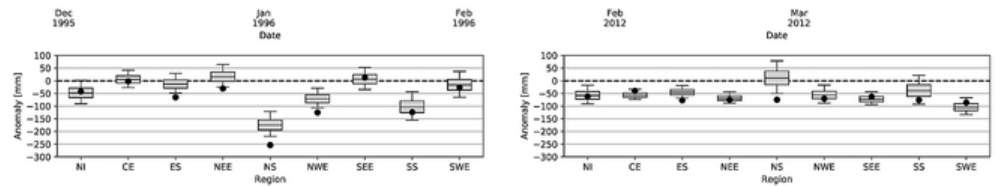

Figure 6

$58 \times 88 \mathrm{~mm}(300 \times 300$ DPI $)$ 


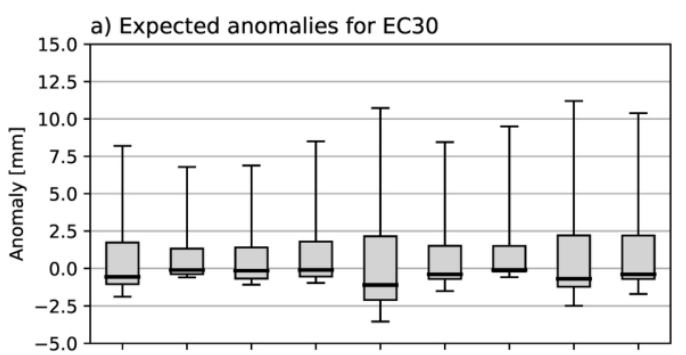

b) Expected anomalies for EC60
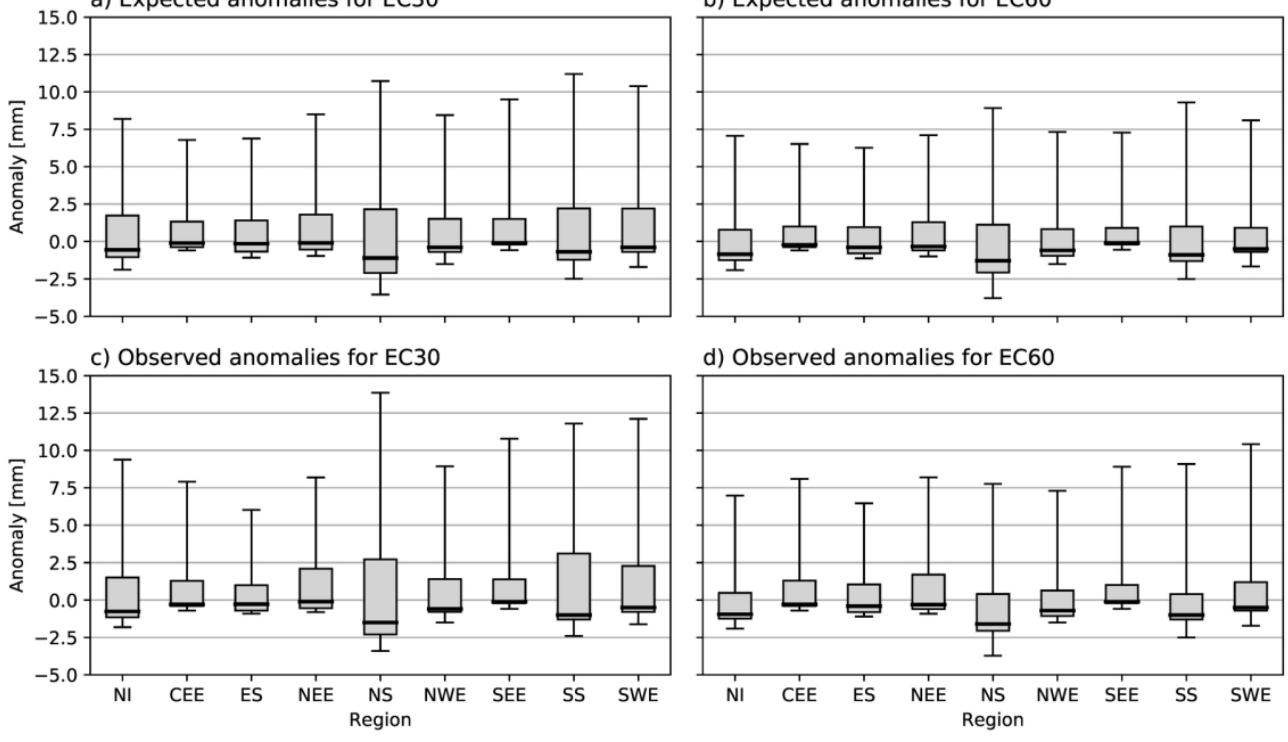

d) Observed anomalies for EC60

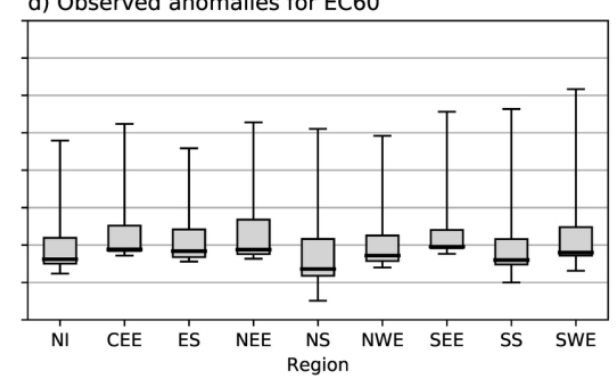

Figure 7

$155 \times 94 \mathrm{~mm}(300 \times 300 \mathrm{DPI})$ 

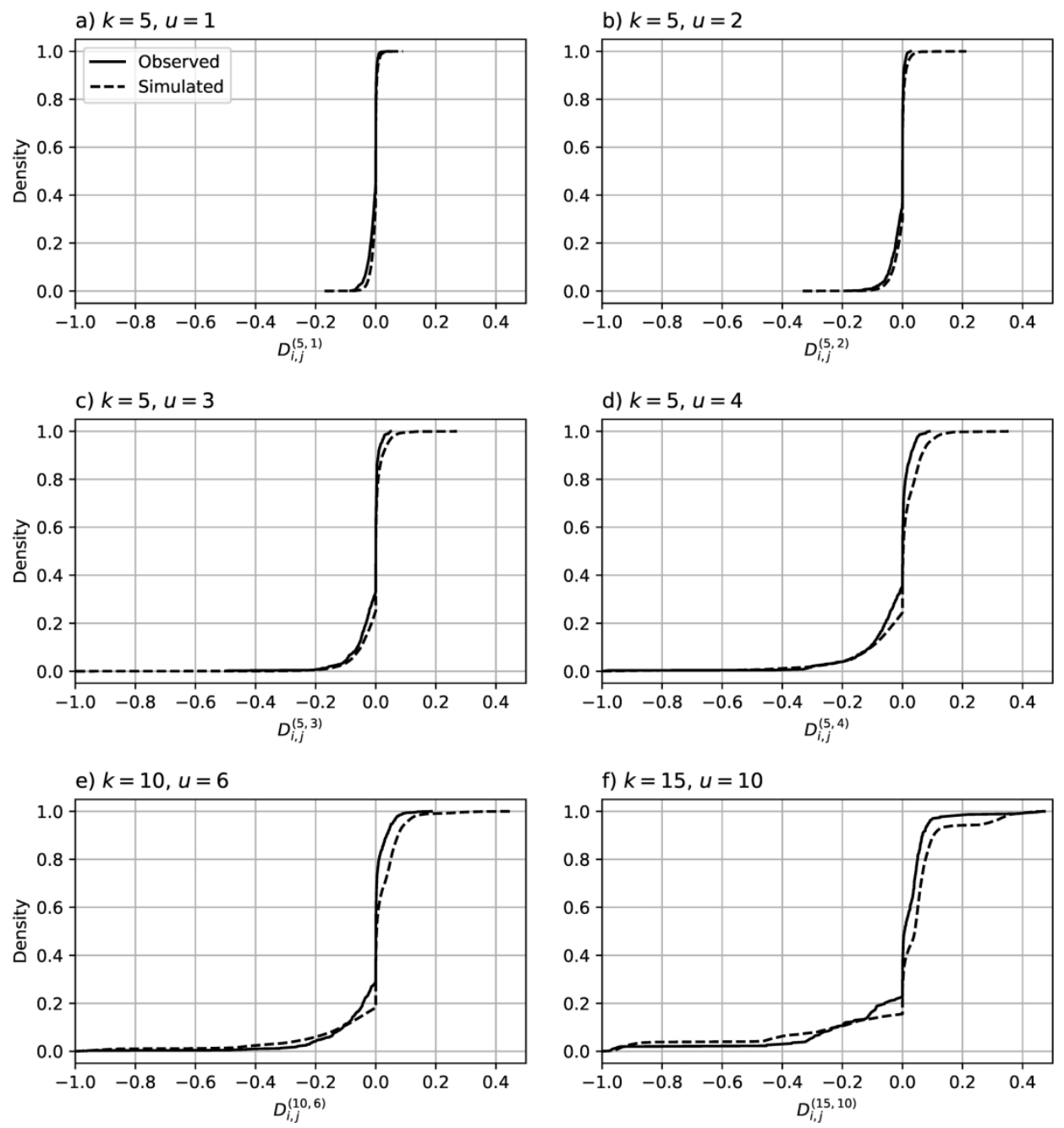

Figure 8

$239 \times 250 \mathrm{~mm}(300 \times 300 \mathrm{DPI})$ 


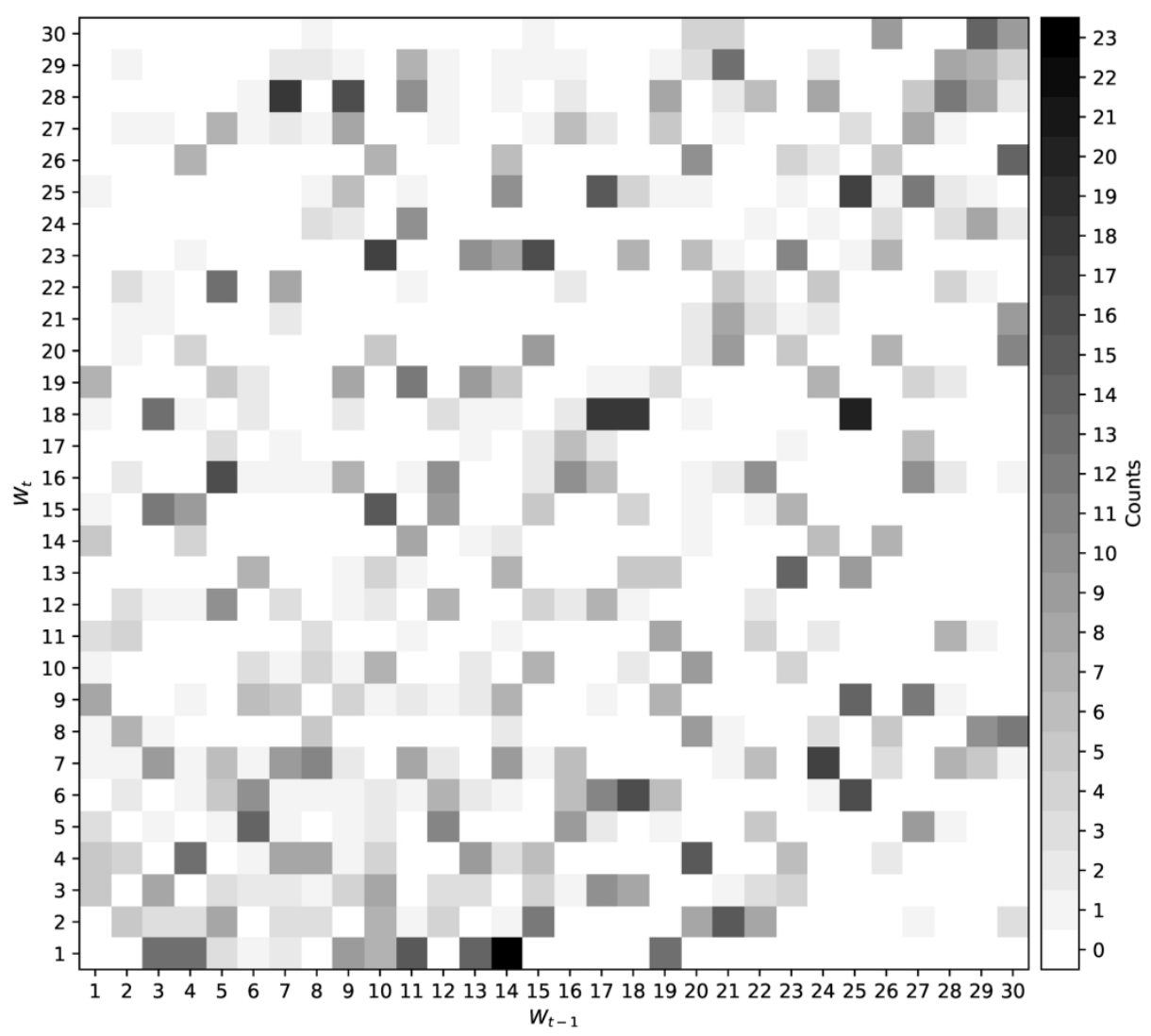

Figure 9

$192 \times 166 \mathrm{~mm}(300 \times 300$ DPI $)$ 


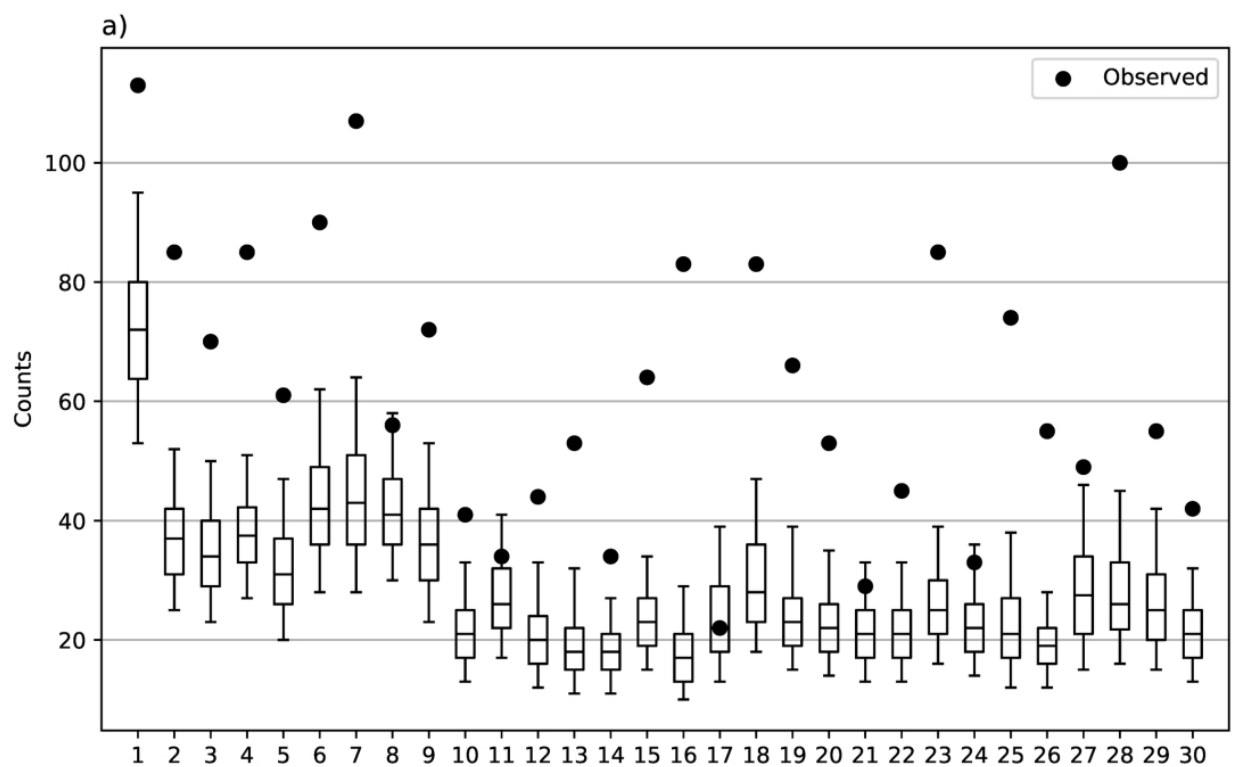

b)

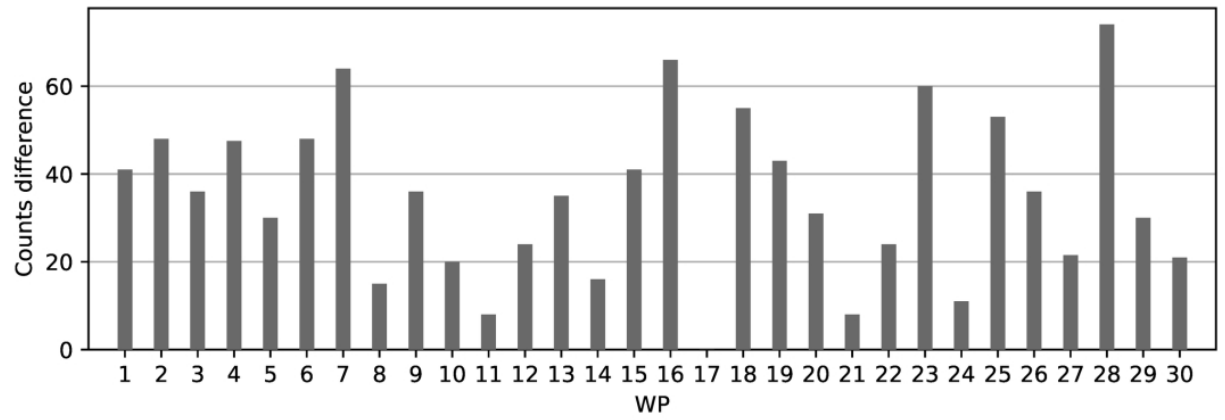

Figure 10

204x199mm (300 x 300 DPI) 


\begin{tabular}{|l|l|}
\hline \multicolumn{1}{|c|}{$k$} & \multicolumn{1}{c|}{$u$} \\
\hline 5 & $1,2,3,4$ \\
\hline 10 & $2,3,4,5,6,7$ \\
\hline 15 & $3,5,7,9,10,11,12$ \\
\hline 20 & $3,5,7,10,12,15$ \\
\hline
\end{tabular}

Table 1: Choices of window length, $k$, and strictness of persistence, $u$, for MM. 


\begin{tabular}{|l|l|l|l|l|l|l|l|l|l|l|l|l|}
\hline Month & Jan & Feb & Mar & Apr & May & Jun & Jul & Aug & Sep & Oct & Nov & Dec \\
\hline EC30 & 25 & 14 & 4 & 2 & 3 & 3 & 9 & 3 & 0 & 0 & 0 & 4 \\
\hline EC60 & 9 & 0 & 9 & 0 & 1 & 22 & 14 & 1 & 0 & 3 & 4 & 16 \\
\hline
\end{tabular}

Table 2: Number of persistence periods beginning in each month. 


\section{Graphical Abstract}

Title: Weekly to multi-month persistence in sets of daily weather patterns over Europe and the North Atlantic Ocean

Authors: Douglas Richardson*, Christopher G. Kilsby, Hayley J. Fowler, András Bárdossy

Persistence in time series of daily weather pattern classifications can provide useful information such as on the memory of broad-scale atmospheric circulation. We develop two novel methods for identifying persistence in a 167-year time series of weather patterns defined over the North Atlantic-European domain, showing that there were multi-month periods when small sets of WPs dominated. Some of these periods coincided with notable meteorological events, such as the Burn's Day Storm over southern Scotland in 1990 (see image). 
b) $S=\{15,20,30\}, S_{f}=\varnothing: 05-01-1990$ to 03-02-1990 (30 days)
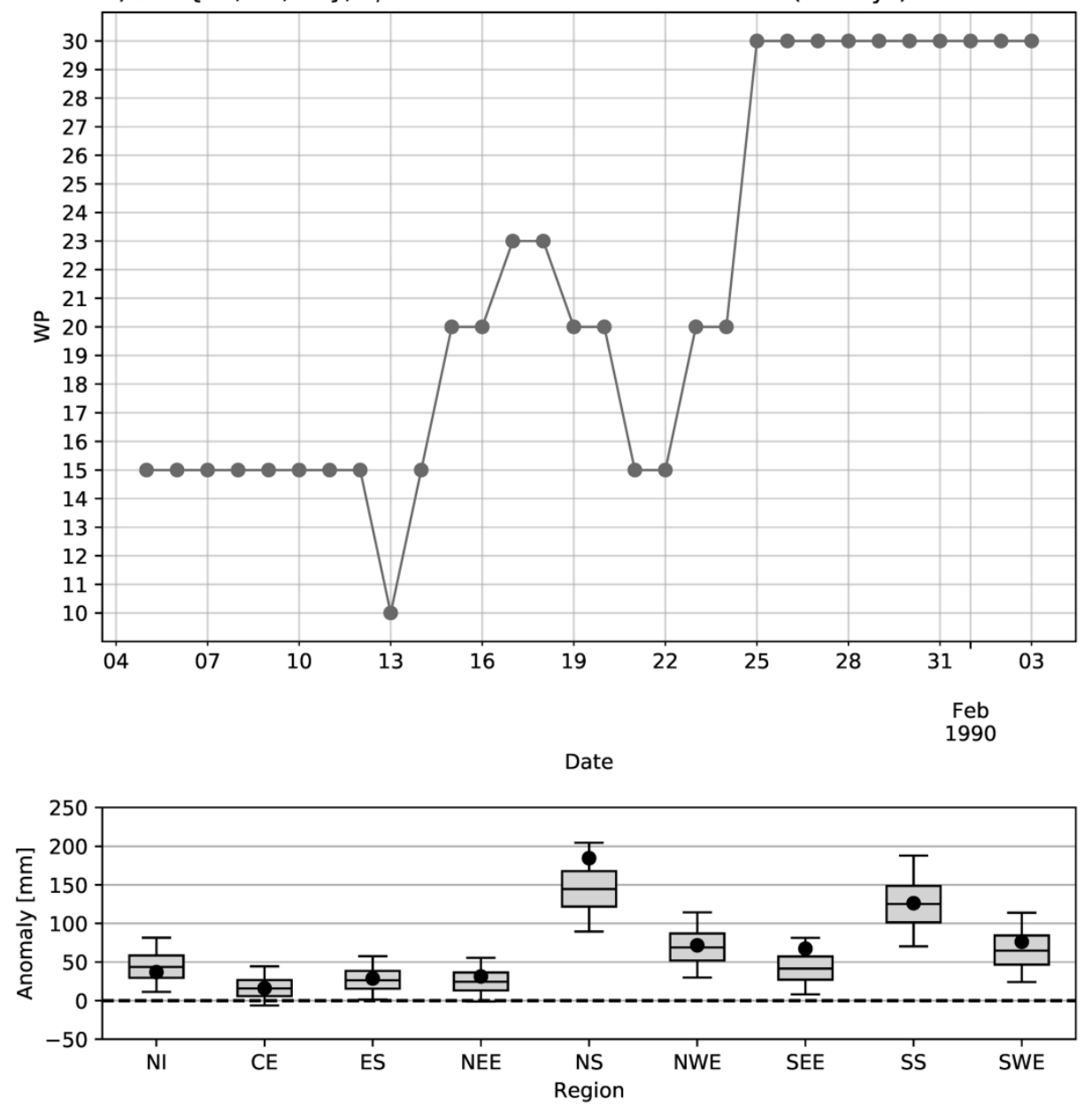

Graphical Abstract

$204 \times 212 \mathrm{~mm}(300 \times 300 \mathrm{DPI})$ 